\title{
Roadmap for Success: Laying Out a Year of Shows
}

\author{
By Linda Bartrom
}

$\mathbf{T}$ he microcosmic world of daily assignments as your students move through the details of production occupies the chief focus of any classroom teacher. An overview of yearly goals guides the instructor through the year-view of content and skills re Television Production, but there is a further consideration for the production teacher and that is the topic of each show. Once formed, it becomes a roadmap for the school year. It provides a sense of grounding in reality for the young production company, coupled with a sense of variety as the year is mapped out season by season. Combined with the layout for each show, which remains the same, the variation of topics for each show provides a valuable lesson for production in general: Every show is different (main topic, e.g. "Football Show") and yet every show is the same (featured parts, e.g. Sports, School News). The seasons provide a natural theme breakdown and within that (analogous to chapters in a book) are the specific show topics covering sports, academics, and social events.

Fall provides topics idiosyncratic to the start of school. Starting with an "Administration Show" has a doubly good effect: It involves your boss(es) in your endeavor and it brings very real information to the community about school rules, any changes in the campus, and the previous year's test scores which highlight academic success. Fall sports provide the basis for multiple shows. For us in southern California it's football, tennis, men's waterpolo, women's volleyball, women's golf, and cross country: Each of these becomes the theme of its own show. A "Welcome Back Dance" for the middle school, and "Homecoming" for high schools plus one or two academic club reports round out topics between sports. My students like to feature student government and Red Cross in the fall. Add a "Red Ribbon Week Show" and a "Halloween Show" and your fall lineup is complete.

Winter brings changes in sports, dances, plays, and thematic holidays. Winter sports for California schools include wrestling, men's and women's basketball, women's waterpolo, and men's golf. A holiday theme can be the basis for a show and typically a winter dance of some type provides another show. In- clude a couple of clubs like chess club, P.A.L. (Peer Assistance Leadership, active in nearly every school), and your drama club or class. The latter by now probably has a production you can feature on a show. Winter also brings science fair or a similar competition, which rounds out your winter lineup.

Spring concludes the year with warm weather sports such as baseball, swimming, and track and field; year-end dances like prom; and graduation and academic awards. In general, including sports and school activities throughout the year increases the chances for students to be filmed in a show's drop-in video, which can be a real bonus in building excitement and enthusiasm for your program. Everybody loves to watch themselves on television, and this builds a steady viewership for your students' productions. Important? Absolutely. What is production without an audience? So build that audience with your yearly lineup and advertise it at school. You will not be sorry! 